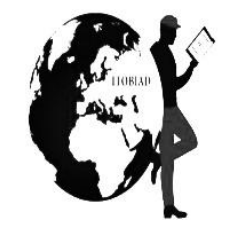

\author{
İNSAN VE TOPLUM BİLIMLERI \\ ARAŞTIRMALARI DERGİsi \\ Cilt / Vol: 7, Sayi/Issue: 2, 2018 \\ Sayfa: 1139-1148 \\ Received/Geliş: Accepted/Kabul: \\ [02-11-2017] - [29-04-2017]
}

\title{
Düzce Kültüründe Ev İle İlgili İnanç Ve Uygulamalarda Eski İnanışlara Dair İzler ${ }^{1}$
}

Hilal ZENGIN

Okutman, Düzce Üniversitesi, Türk Dili Bölüm Lecturer, Duzce University Department Of Turkish Language orcid.org/0000-0001-7844-7708

hilaldemir@duzce.edu.tr

Çiğdem SÜTCÜ

Okutman, Düzce Üniversitesi, Türk Dili Bölümü Lecturer, Duzce University Department Of Turkish Language orcid.org/0000-0001-8841-3069

Öz cigdemsutcu@duzce.edu.tr

İnsanoğlu eski devirlerden beri pek çok dinî inanışın etkisi altında kalmıştır. Her devirde bu inanışlar etrafında birtakım uygulamalar şekillenmiş ve bu uygulamalardan bazıları nesilden nesle aktarılmak suretiyle farklı şekillerde günümüze kadar ulaşmıştır.

Bu çalışmada Düzce'de yaşayan topluluklar arasında görülen "ev" ile ilgili inanışlar ve uygulamalar değerlendirilmiş, konularına göre sınıflandırılmış, bu inanış ve uygulamalarda eski inanışlara dair izler ortaya konmaya çalışılmıştır.

Çalışmamızda yer alan bilgiler, saha çalışması yapılarak ve yüz yüze görüşme yöntemi kullanılarak kaynak kişilerden derlenmiştir. Kimi zaman gruplar ile kimi zaman da bireysel görüşmeler yapılarak bilgiler toplanmış, alınan cevaplar ses kayıt cihazı ve kamera ile kaydedilmiş ve deşifre edilen bilgiler incelenmiştir.

Anahtar Kelimeler: Düzce, Kültür, Ev, İnanış, Uygulama.

\section{Traces of Old Beliefs on the Beliefs and Practices Concerning "Home" In the Local Culture of Düzce}

\section{Abstract}

Humankind has been under the influence of various religious beliefs since ancient times. In each era, there have been some practices based on these beliefs, passed down from generation to generation; some of these practices have survived to the present day in different forms.

In this study, the beliefs and practices regarding "home" of different ethnic groups living in Düzce have been reviewed and categorized into subgroups based on their topics. Traces of old beliefs on these subjects were determined.

The data were compiled from local people through a field study by using face-to-face interview method. Both individual and group interviews had been carried out to collect data. The interviews were digitally recorded with sound recorders and video cameras and these records have been examined.

Keywords: Duzce, Culture, Home, Belief, Practice.

\footnotetext{
${ }^{1}$ Bu makale, Düzce Üniversitesi BAP kapsamında yürütülen “Düzce'de Halk Edebiyatı, İnanışlar, Geleneksel Giyim ve Mimari" adlı 2011.03.06.067 nolu proje çerçevesinde hazırlanmıştır.
} 


\section{Giriş}

Düzce, başta Balkanlar ve Kafkaslar olmak üzere yurt içi ve yurt dişı pek çok bölgeden göç almış, çeşitli sebeplerle topraklarından ayrılmış topluluklara yurt olmuştur. Bugün Abhazlar, Arnavutlar, Boşnaklar, Bulgaristan göçmenleri, Çerkezler, Dadaşlar (Erzurumlular), Hemşinliler, Karadenizliler (Ordulular, Giresunlular, Trabzonlular), Kırım Türkleri, Kürtler, yerli Türkler ve Gürcüler Düzce'de belli bir nüfus yoğunluğuna sahip olan topluluklar olarak karşımıza çıkmaktadır. Düzce'de yaşayan her topluluk kendi kültürüne ait izleri, gelenekleri, âdetleri ve bunlar çerçevesinde şekillenen inanış ve uygulamaları belli oranlarda yaşatmaya çalışmış, aynı zamanda yüzyıllardan beri bu topraklara ait olan kültürel birikimden de büyük ölçüde etkilenmiştir.

Somut olmayan kültürel miras içinde yer alan inanışlar, geçmişten günümüze insanoğlunun yaşamını etkilemiş, etkilemeye de devam edecektir. Her kültürde olduğu gibi semavi dinler öncesi inanç sistemlerinden semavi dinlere geçen toplumlar eski âdet ve inanışlarını birdenbire bırakmamışlardır. Yeni dinlerinin özüne ters olsa da bazılarını yeni dinlerinin rengine ve kalıbına sokarak o dinin gereğindenmiş gibi uygulamışlardır (Artun, 1998: 66). Anadolu'da da İslam öncesi inanışların İslam'dan sonra da devam ettiği görülmektedir. Çalışmamızın konusunu Düzce'de geçmişte var olmuş ve hâlâ varlığını sürdüren âdet ve gelenekler içerisinde "ev bark" ile ilgili uygulama ve inanışlar oluşturmaktadır.

\section{Ev Bark Kelimesinin Kökeni}

Güncel Türkçe Sözlük'te ev kelimesi: "1. Yalnız bir ailenin oturabileceği biçimde yapılmış yapı, 2. Bir kimsenin veya ailenin içinde yaşadığı yer, konut, hane, 3. Aile, 4. Soy, nesil" anlamlarını karşılamaktadır (Ev, t.y.). En eski metinlerimiz olan Köktürk Kitabeleri'nde karşımıza çıkan ev kelimesi, “äb bark 'ev bark' (BK D 32) olarak ikileme şeklinde ve äb 'ev, çadır; kamp yeri, yurt'" anlamlarında kullanılmaktadır (Tekin, 2001: 8). Eski Türkçede "eb" şeklinde söylenen sözün Selçuklular döneminde "ev" e dönüştügünü söyleyen Ögel (1971), “ev bark" sözcügüyle ilgili şu bilgileri vermektedir:

“Ev sözü eski Türkçede 'eb' şeklinde söylenirken Selçuk çağının başlarında artık bu söz ev şekline girmiştir" "Bark sözü, Hakan sarayı için kullanılan, eski bir Türk deyimi olmalıdır. Öyle anlaşılıyor ki Türkler, ilk zamanlarda taştan yapılmış yapılara bark diyorlardı. Bu yapılar, genel olarak taştan yapılırlar ve ölen atanın resimleri, heykelleri ve türlü hatıraları da bu bina içinde saklanırdı. Diğer yandan bark sözü, ev anlamına da gelirdi. Bu söz, genel olarak yalnız kullanılmaz ve bugünkü Türkçemizde olduğu gibi, $e b$ bark, yani ev bark şeklinde söylenirdi. Bugünkü ev sözümüzün karşılığ1 da eski Türkçede eb idi. ev şimdiki gibi, ev anlamına geldiği kadar, aile karşılığında da kullanılırdı" (s. 132-133).

Ev kelimesi biçim olarak zaman içerisinde değişim gösterse de Anadolu'da sadece barınma ihtiyacını karşılayan bir yapı değil, aynı zamanda aileyi bir 
arada tutan, aile bireylerinin birbirleriyle olan bağlarını kuvvetlendiren, onları maddi manevi dış etkilerden koruyan bir nevi mabet olma özelliği taşımaktadır. Aile birliğinin korunmasında son derece önemli olan ev ile ilgili pek çok inanış ve bu inanışlar çevresinde şekillenen uygulamalar ortaya çıkmıştır. Günümüzde ev ile ilgili uygulamaların bir kısmı İslam öncesi bir kısmı ise İslami temele dayandırılabilir.

\section{Evin İnşası ile İlgili İnanışlar}

Düzce'de evin temelinin atılmasından çatısının bitmesine kadar her aşamada eski inanışların izlerini görmek mümkündür. Düzce'de karşımıza çıkan evin temeli atıldığında kurban kesme, kan akıtma uygulaması günümüzde her ne kadar İslami temele dayandırılsa da bu uygulamanın İslam dininin doğuşundan çok önceki çağlara kadar uzayabileceğini söyleyebiliriz. İnsanoğlu inandıkları dinin gereği her zaman kurban sunma eyleminde bulunmuşlardır. Geleneksel Türk dinî inanışları içerisinde en köklü ve günümüze ulaşan inanışlardan olan kanlı ve kansız olmak üzere ikiye ayrılan kurban ibadeti, hangi dine mensup olursa olsun bütün Türk toplulukları tarafından yerine getirilmektedir (Güngör, 2007: 3-4). Örneğin Manas destanında birçok yerde at kurbanı geçmektedir: "Manas'ın oğlu Semetey Talas'ta Zülfikâr dağında oturan Bayoğlu Bakay'ı ziyaret eder. Bakay sevinir. Tanrı yoluna atlar kurban eder" (Ögel, 1993: 534). Eski Türk mitolojisinde ise kötülüğün, ölümün, ölülerin ve yer altının Tanrısı olan Erlik, insanlara her türlü kötülükleri yapar; insanlara ve hayvanlara türlü türlü hastalıklar göndermek suretiyle kurbanlar ister. İstediği kurban verilmezse musallat olduğu obaya veya aileye ölüm ve felâket ruhlarını gönderir" (İnan, 1995: 39). Geçmişte ruhlar için kesilen bu kurbanlar, günümüzde yerini şükran ve kefaret için kesilen kurbanlara bırakmıştır. Geçmişten bu yana kurban inancının bir yansıması Düzce'de şu şekilde karşımıza çıkmaktadır:

"...eskiden de vardı, bugün de var. Yeni ev yapilırken temele bir kan akıtılır. Ama bir koyun kesilir ama bir horoz kesilir. Yalnız onun etini ev halkı yemez. Adaktır." (KK: Kenan Çiçek, Abhaz)

"Evin temeli atılirken kurban keserlerdi ya da mesela adamin durumu yok, getirir bir horoz keser, temeline kan akıtır." (KK: Nuri Yıldız, Gürcü)

"Evin temelini atarlarken Kürtler vardl, kan isteriz dediler o zaman da koyunlarımız çoktu, o gün denk geldi, bir koyun onlara verdim, afiyetle yediler. Mevlit yapan yapıyor." (KK: Lütfiye Özen, Çerkez)

"Temel atıldığı zaman kan döküyoruz. Ama o kişinin bildiği tavuk da keser, dana da keser. Ev bittiğinde mevlit yapılır. Örneğin burada bir ev yapıldı̆̆ zaman dostların çağırıyorsun güzel bir mevlit okutuyorsun." (KK: A. Osman Kurnaz, Kürt)

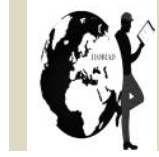


"Evin temelini atarken tavuk keseriz ustalara. Kan akıtılacak. Mevlit okuturuz, çatıya bayrak dikeriz. Sıva sıvaladılar bahşiş verdim." (KK: Ayşe Melenlioğlu, yerli Türk)

Düzce'de evin temeli atılırken kurban kesme, ev bittiğinde mevlit okutma İslam öncesi ve sonrası inanışların iç içe olduğu örnekler olarak karşımıza çıkmaktadır.

Evin inşası ile ilgili bir diğer uygulama ev bittikten sonra çatıya bayrak dikilmesidir. Bayrağın inşası henüz bitmiş bir evin çatısında, bir düğün evinde, köye hâkim bir tepede, şehit ocağında ya da bir askerin evinde olması manidardır. Bayrak; bir saygınlık gösterme, gururu, zaferi, övgüyü duyurma simgesi olarak dikileceği yer ile birbirini bütünleyerek, o yerin kime ait olduğunu, zamanın hangi aşamasında (evlilik, askerlik vb. çağı) bulunulduğunu, orada hangi önemli sürecin/olayın yaşandığını anlatmaktadır. Yaşanılan durum, bayrak dikerek dosta-düşmana duyurulmaktadır (Işık, 2013: 22).

Bayrak, kültürümüzde yüklendiği anlamlar ile hayatımızda önemli bir yere sahiptir. Evin inşası sonrasında bir uygulama olarak karşımıza çıkan bayrak, evin kültürümüzde ne denli öneme sahip olduğunu gösteren bir simgedir. Eski Türk geleneğinde Hakan çadırı kurulduktan sonra, tuğlar ve bayraklar dikildiğini ve davullar çalındığını görmekteyiz (Ögel, 1971: 136). Ayrıca tŭ̆g veya tuk denilen beyaz kumaştan yapılma bayrakların evi kötü ruhlardan koruduğuna inanıldı̆̆ı da görülmektedir (Ögel, 2000: 200).

Düzce'de de evin çatısı inşa edildiğinde çatıya bir bayrak dikilmekte ve bu sayede yeni bir evin yapıldığı konu komşuya ilan edilmektedir:

“...ev bittiği zaman da o bina tamamlanıp da çatı çakılırken en son artık mengeneyi çakarken tepede oturur usta, güzel ahenkli bir ritmik ses çıkartır çiviye vurarak, hediye ister. Komşuları basma idi, yazma idi. Şuydu buydu bayrak asılır. O gelen şeyler de ustalarındı." (KK: Kenan Çiçek, Abhaz)

"Ev bitti çatı yapıldı bayrak asılır. Mesela kiremit döşenecek, oraya şöyle $T$ şeklinde bir şey çakılır, ona havlular bağlanır, evi yaptıran havlu takar, kumaş elbiselik kumaşlar. Komşular, yakın komşular, tanıdıklar getirirler oraya havlulu hediye getirirler, kumaş getirirler. Hediyeler çatıyı yapan ustanın." (KK: Kıymet Aydın, Arnavut)

"Ev yapıldiğında bayrak asarlar tepeye, çatıya." (KK: Nurten Şahin, Bulgaristan gö̧̈meni)

“...bayrak asıllyor. O zaman konu komşu kimi havlu getiri kimi bir iki metre basma getirir." (KK: Lütfiye Özen, Çerkez)

Evin inşasında bir inanış ve uygulama olarak karşımıza çıkan bayrak, yeni yapılan eve hediye götürme, evi yapan ustalara hediye verme gibi âdetler ile de kültürün içinde yer almaktadır. 


\section{Bereket ile İlgili İnanç ve Uygulamalarda Ev}

Kültürümüzde bolluk ve bereketle ilgili inanışlar, son derece çeşitlilik göstermektedir. Anadolu'nun birçok yerinde eski inançlarımıza bağlı olarak evin bereketi ile ilgili inançlar yaşamaktadır. Evin en önemli noktalarından sayabileceğimiz kapı ve eşik evin içine giriş izni veren, aynı zamanda giriş sırasında gelene eve girmekte olduğunu hatırlatan ilk duraktır. Ev iyesi (Türk kültüründe evin koruyucu ruhu) eşikte olabilir. Onu incitmeden içeri girmek gerekir" (Kalafat, 2010: 182). Düzce'de kapının eşiği ile ilgili düğünlerde gelin eve girerken karşımıza çıan inanış ve uygulamalar şunlardır:

"Şimdi eşikten içeriye girerken iki tane delikanlı kapıya dikilir. Birinde silah vardır, birinde bıçak vardır. Bu şekil çaprazlama. Ana kapıya durur, giriş kapıya. Gelinin să̆ kolunun altına Kuran-ı Kerim, sol kolunun altına ekmek. Silah ve bıçak kutsal olarak kabul edilir. Kuran-ı Kerim'in koltuğunun altına verilmesi, dünyaya getirecek olan çocuklarmın ilim irfan sahibi olabilmelerini ve yüce dinimizin bütün buyrukları içeresinde olan kutsal kitabımız. Ekmek bereketi ifade ediyor. Ve gelin kapıdan içeriye girerken, sağ ayağıyla girer, kesinlikle sol ayă̆ıyla girmez." (KK: Kenan Çiçek, Abhaz)

"Gelin eve girerken ekmek ve kuran koyulur. Kapıya yağ bal sürülür üç kere. Bardak kırılır. Kapıya çivi çakılır. Eve su dökerek girer." (KK: Sadi Duran, Bulgaristan göçmeni)

"Ben kapıdan girerken iki tane toprak ibrĭgi kırdım. Dış kapıdan içeri girerken kır dediler, vurdum kırdım ibriklerini." (KK: Zeynep Batman, Bulgaristan göçmeni)

"Bizde de bir bıçak kapının ă̆zına, bir bıçak bir de silah. Bereket olması için ekmek. Bıçak, silah işte o bir sembol olarak yani işte güvenli bir şekilde, güvenli bir yere geldiğini anlatır. Silah da şimdi eskisi gibi kullanılmıyor bir kama bıçak kullamllyor, koltuğunda ekmek, onun altından geçip gidiyor işte." (KK: Aydın Aydoğan, Abhaz)

"Bir de gelin kapıya geldiği zaman bardak koyarlar ayağının altına. Basar, kırılır bardak. Uğurlu olsun diye." (KK: İsmail Balık, Dadaş)

"Kayınvalidesi şeker atar. Kapıya gelin bir çivi çakar, o eve yapışsın o evde kalsın diye Eşikten basar tabă̆ı kırar." (KK: Hüseyin Karabulut, Kürt)

Anadolu'da bazı bitkiler bereketin ve bolluğun simgesi olmuştur; insanlar bu bitkileri evlerinin bir köşesinde bulundurarak bolluk bereketi arttırmayı amaçlamışlardır. Düzce'de bolluk bereket getireceğine inanılan bitkilerin, meyvelerin, çeşitli gıda maddelerinin evlerde kullanımı ve uygulamaları şöyledir:

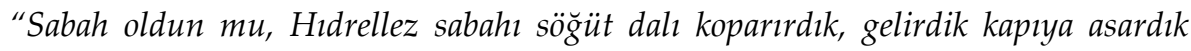
onları." (KK: Kıymet Aydın, Arnavut) 
“... aşure günü girdiği zaman sabah hiçbir şey yapmadan evine birkaç erzak alırsan, inanışlara göre bereketli geçecek şeyine gidiyorlar. Bugün aldın mesela meyve, sebze, ufak tefek şeyler, evine getirirsen bereket artar inancı yüksek. Aşure dağıtırlar bizim buralarda. Aşure yaparlar, kaç çeşitten karıştırırlar, onları pişirirler. En az yedi kişiye, artık kazan yetinceye kadar herkese dă̆ıtırlar." (KK: Ümmet Alkan, Laz)

"Hıdrellez'de kapılara kemik de takarlar sabahleyin. Biz darı dökerdik, evin etrafina. Bu akşam toplarlar derdi nineciğim, kızanım derdi dökün darıyı derdi. Darı bulgurun bir incesi. Isırgan toplanır. Isırganı bağlarsın. Ĕ̆ger ısırgan sararsaydı bağlayan ölürmüş. Herkesin kapısına gidiyoruz ısırgan duruyor." (KK: Makbule Şahin, Bulgaristan göçmeni)

En çok avcılıkla geçinen toplumlarda görülen hayvan kültü, hayvan ile insan arasındaki dinsel ve büyüsel bir ilişkinin çevresinde toplanmıştır. Bu toplumlarda hayvanlar büyük bir önem kazanmış, bu önem giderek kutsal bir niteliğe bürünmüş ve kimi zaman da bazı hayvanlar bolluk bereketin simgesi olmuştur(Artun, t.y.: 16):

"Pösteki sererlerdi içeriye gelin içeri girerken. Pöstekiyi bereket için sererler." (KK: Kevser Akan, Abhaz)

Anadolu'da karınca bolluk ve bereketin sembolüdür. Çalışkanlığı ile bilinen bir hayvan olan karıncanın, geldiği eve bereket getirdiğine inanılır ve asla ona zarar verilmez. Evlerde karınca duası bulundurmak da bereket sembolü olarak görülmektedir:

"Karınca yuvasından kum alını un ambarına koyulur bereket için. Kapıya süt koyulur Hızır mayalasın diye. Komşuya süt ya da maya Hıdrellez'den önceki akşam verilmez." (KK: Sadi Duran, Bulgaristan göçmeni)

"Karınca bizde berekettir, her evde genelde çıkar. Topraktır evler. Çünkü toprak olmasindan mütevellit de her tarafindan karınca çıkar. Karıncaya dokunmazlar." (KK: Hasan Durmaz, Selanik göçmeni)

\section{Kötülüklerden Korunma ile İlgili İnanç ve Uygulamalarda Ev}

Düzce'de evi ve içerisinde yaşayanları kötülüklerden korumaya yönelik uygulamalar farklı şekillerde karşımıza çıkmaktadır. Uygulamalar kimi zaman yeni doğan bebeği ve annesini kötü ruhlardan ve nazardan korumaya yönelik kimi zaman da evi kötülüklerden korumaya yöneliktir. Bu uygulamalardan bazı örnekleri şöyle sıralayabiliriz:

"Bir dizi biber asılıyor, nazar gelmesin diye kırmızıbiber." (KK: Resmiye Aman, Laz)

"Bebeğgin göbek bă̆ını o an düştü mü onu halının altına koyarız. Orada bir zaman durur. Nazar değmesin diye. Temiz ya. Şu kapının orda halının altına koyarız. (KK: Kiymet Aydın, Arnavut)

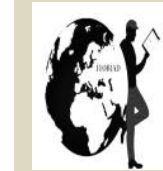


"ilk kakası, ilk bezi o da saklanır o da kapıya konur. Üstünden geçsinler, nazar değmesin. Batıl inanç ama inanılır." (KK: Sadiye Aydın, Abhaz)

"Bildiğgimiz file var ya file asarlardı. Cadı geliyormuş, cin geliyormuş da o onu koruyormuş. Kapının arkasına file parçasını asarlardı. Mesela ahıra asarlardı." (KK: Recep Aman, Laz)

“...cıva bakır, karabiber, pul biber bunların hepsini iç içe koyarak hani muska gibi yaparlar, böyle üçgen şeklinde olur. Evin görünmeyen bir yerine konurdu. İşte bu kazadan beladan, afetlerden korusun diye." (KK: Kenan Çiçek, Abhaz)

Demir ve süpürgenin evi ve içinde yaşayanları kötülüklerden koruyacağına dair yaygın bir inanış bulunmaktadır. Eski Türkler, demirin şeytanları kovduğuna özellikle demirden yapılan bıçakların ekinleri, kötü havaya karşı, kem gözlere karşı koruduğuna inanmaktadırlar (Türkmen ve Türker, 2014: 4). Süpürge de Türk kültüründe, bereketin celbinde ve korunmasında, kara iyelerden korunmak ve zararlarından kurtulmak konusunda çeşitli uygulama biçimleri ile karşımıza çıkmaktadır (Kalafat, t.y.: 1). Düzce'de demir ve süpürge ile ilgili inanışlardan bazıları şunlardır:

"Kapının eşiğine süpürge koyarlar. Biz demir takıyoruz." (KK: Makbule Şahin, Bulgaristan göçmeni)

"Kapının eşiğinde demir olur. Ama şimdi onlar yok. Kırk basığı falan olmuyor. O zaman kırk basığı olurdu. Üzerine geldi mi seninki zayıf kalırdı. Şimdi hastanede doğuyor çocuklar tartıllyor. Şimdi öyle şeyler hiç kalmadı." (KK: Zeynep Batman, Bulgaristan göçmeni)

Düzce'de yaygın olarak karşımıza çıkan bir diğer uygulama da "evden dişarıya tuz verilmemesi"dir. Günümüzde sıklıkla rastlanan, okunmuş pirinç, tuz, şeker ya da benzeri maddelerin yenilmesi, yutulması, muskaların giysilere iliştirilmesi, duaların yazılı olduğu kolyelerin, yüzüklerin takılması vb. inanmaların birer "temas büyüsü" uzantısı olabileceği düşünüldüğünde bu uygulamanın kötülüklerden korunma ile ilgili bir önlem olduğunu; diğer taraftan tuz, şeker, un vb. maddelerin bereket sembolü olması nedeniyle de tuzun evden dışarı verilmediğini söyleyebiliriz (Artun, t.y., s. 19):

"Bir de evden tuz vermezler şey olmasın diye evin tadını götürürmüş. Başkasına evden sadaka olarak tuz verdiğinde verdirmezler, evin tadın götürürmüş derler. Tuz verilmez onun dışında her şey veriliyor tuz vermezler." (KK: Ayşe Seven, Dadaş)

Türk kültüründe geçmişten günümüze kadar at nalı, geyik boynuzu, koç kafası vb. nesneler nazarı önlemek amacıyla kullanılmıştır. Bu nesnelerin Düzce'de kullanımı şöyledir:

“... boynuz çakıyor, nal çakıyor bole şeyle vardı." (KK: Resmiye Aman, Laz)

"Kazadan beladan korunmak için herhalde at başı asarlardı, kurukafa." (KK: Turan Özcan, Abhaz) 
"Eve nazar boncuğu, nal çakarlardı." (KK: Hasan Sevinç, Kürt)

Geyik Türkler tarafından kutsal bir hayvandır. "Türk mitolojisinde, masallarda ve efsanelerde geyik motifine rastlanır. Geyik, avcıları peşinden çekerek onları Kaf dağına götürür. Dağ yarılır ve geyik gözden kaybolur (Artun, t.y. s. 16). Geyik ile ilgili karşımıza çıkan bir uygulama şöyledir:

"Geyik vurdular mı boynuzu hemen evinin eşiğinin başına takarlardı." (KK: Nuri Yıldız, Gürcü)

\section{Sonuç}

İnanışlar, Türk halk kültürü içerisinde geçmişte olduğu gibi bugün de varlığını sürdürmeye devam etmektedir. Kimi zaman İslami bir karaktere bürünmüş şekliyle, kimi zaman ise "batıl" olarak nitelendirilen şekliyle karşımıza çıkan inanışlarda eski inanışlara ait izleri görmek mümkündür.

Düzce halk kültüründe ev ile ilgili inanışlar evin inşasında, evlilik törenlerinde, Hıdırellez'de ve günlük yaşam içinde evin eşiği, kapısı ya da duvarında uygulanan bir pratikle evin uğurunu ve bereketini artırmaya yönelik karşımıza çıkmaktadır.

Bir evin temeli atıldığında kurban kesilmesi, evin çatısı bittiğinde çatıya bayrak dikilmesi, evin inşası sırasında karşımıza çıkan uygulamalardır.

Evlenme ile ilgili inanışlarda gelin eve girerken, eşiğe bal sürmesi, kapıya çivi çakması, bir kolunun altına ekmek verilerek eve girmesi gibi uygulamalar evin uğurunu ve bereketini arttırmaya yönelik uygulamalardır.

Bazı bitkilerin -sögüt dalının kapıya asılması gibi- evde bulundurulmasının, bir yere asılmasının evde bereketi arttıracağına inanılmaktadır.

Yine Türk inancında önemli bir yere sahip olan hayvanların kimi zaman postu bereket sembolü olmakta, kimi zaman da boynuzu kötülüklerden korunmak amacıyla evin bir köşesine asılmaktadır.

Evi ve evde yaşayanları kötülüklerden korumak amacıyla demir, süpürge, geyik boynuzu gibi nesnelerin kullanılması eski Türk inanışına ait izleri görebildiğimiz örneklerdir.

\section{Kaynak Kişiler}

KK: Ali Osman Kurnaz, 55 yaşında, Düzce-Bahçeköy.

KK: Aydın Aydoğan, 1952 doğumlu, Düzce-Kaledibi.

KK: Ayşe Melenlioğlu,1930 doğumlu, Düzce-Ozanlar

KK: Ayşe Seven, 31 yaşında, Erzurum.

KK: Hasan Durmaz, 1961 doğumlu, Düzce-Akyazı.

KK: Hasan Sevinç, 26 yaşında, Düzce-Paşakonağı.

KK: Hüseyin Karabulut, 1964 doğumlu, Düzce-Bahçeköy. 
KK: İsmail Balık, 61 yaşında, Erzurum.

KK: Kenan Çiçek, 1953doğumlu, Düzce-Konuralp.

KK: Kevser Akan, 82 yaşında, Düzce-Yeşilyayla.

KK: Kıymet Aydın, 71 yaşında, İstanbul.

KK: Lütfiye Özen, 67 yaşında, Düzce-Tahirağa.

KK: Makbule Şahin, 83 yaşında, Düzce-Selamlar.

KK: Nuri Yıldız, 1948 doğumlu, Düzce-Açmalar.

KK: Nurten Şahin, 56 yaşında, Düzce-Selamlar.

KK: Resmiye Aman, Resmiye Aman, 58 yaşında, Düzce-Kabalak.

KK: Sadi Duran, 70 yaşında, Düzce-Yakabaşı.

KK: Sadiye Aydın, 1960 doğumlu, Düzce-Merkez.

KK: Turan Özcan, 72 yaşında, Düzce-Derdin.

KK: Ümmet Alkan, 32 yaşında, Düzce-Kabalak.

KK: Zeynep Batman, 67 yaşında, Düzce-Fevziye.

\section{Kaynakça}

Artun, E. (1998). Tekirdă̆ halk kültürü araştırmaları. Tekirdağ: Tekirdağ Genç İşadamları Derneği Kültür Yayınları.

Artun, E. Türklerde İslamiyet öncesi inanç sistemleri - öğretiler-dinler.

Erişim adresi:

http://turkoloji.cu.edu.tr/HALKBILIM/erman_artun_inanc_sistemleri.pdf

Ev. (t.y.). Türk Dil Kurumu güncel Türkçe sözlük içinde. Erişim adresi:http://www.tdk.gov.tr/index.php?option=com_gts\&arama=gts\&guid= TDK.GTS.5a86ed96720629.40848656

Güngör, H. (2007). Geleneksel Türk dininden Anadolu'ya taşınanlar. Yaşayan Eski Türk Inançları Bilgi Şöleni: Bildiriler kitabı içinde (s.1-6). Ankara: Hacettepe Üniversitesi Türkiyat Araştırmaları Enstitüsü Yayınları.

Işık, S. Y. (2013). "Türkiye'de okuma alışkanlığı sorununa antropolojik bir yaklaşım işlevsel okuryazarlığın Türk kültüründeki anlamı: Ücret köyü örneği ". Eleştirel Pedagoji, 30, 41-56.

İnan, A. (1995). Tarihte ve bugün Şamanizm. Ankara: TTK Yayınları.

Kalafat, Y. (2010). Doğu Anadolu' da eski Türk inançlarının izleri. Ankara: Berikan Yayınevi. 
Kalafat, Y. Türk kültür coğrafyasında süpürge inancı. Erişim adresi: http://www.turkcuturanci.com/turkcu/turk-toresi/turk-kultur cografyasinda-supurge-inanci/?wap

Ögel, B. (1971). Türk kültürünün gelişme çağları. İstanbul: Milli Eğitim Basımevi.

Ögel, B. (2000). Türk kültür tarihine giriş. T.C. Ankara: Kültür Bakanlığı Yayınları.

Ögel, B. (1993). Türk mitolojisi (kaynakları ve açıklamaları ile destanlar), C.I, 2. bs. Ankara: TTK Yay.

Tekin, Ş. (2001). İştikakçının köşesi Türk dilinde kelimelerin ve eklerin hayatı üzerine denemeler. İstanbul: Simurg Yay.

Türkmen, F., Türker, F. (Yaz 2014). Geleneklerde ve inançlarda demir. Türk Dünyası İncelemeleri Dergisi / Journal of Turkish World Studies, XIV(1). 